\title{
Commentary: cause and effect in occupational lung disease
}

\author{
P S Burge
}

All disease has causes - the difficulty is differentiating associations from aetiological factors. Chest physicians and occupational physicians are better than most at finding the cause of diseases. If an unusual disease or disease cluster occurs in a workplace, an occupational physician will usually have to explain whether or not the disease is caused by the workplace. In this month's Thorax there are three case reports which have linked occupational exposures with disease. Attribution of a causal relationship from case studies is most difficult when the latency period from exposure to disease is long.

Studnicka and colleagues describe a case of systemic sclerosis in a worker with pneumoconiosis following exposure to polyvinyl chloride (PVC) dust. Both are rare diseases and the chance of them being seen in the same individual is therefore small but not negligible (and enhanced by recording bias which tends to favour publication). The authors provide additional support for their causal hypothesis. Systemic sclerosis has been associated with other pneumoconioses, particularly with silica and coal. ${ }^{1}$ A very similar disease (acro-osteolysis) was seen in workers heavily exposed to vinyl chloride, the precursor of PVC. ${ }^{23}$ Finally, they postulate a mechanism by which the PVC could cause systemic sclerosis. They found that the alveolar macrophages in their worker contained undigested PVC particles; non-digestible particles in alveolar macrophages were also a feature in the other individuals with pneumoconioses associated with systemic sclerosis. It is possible that these non-digestible particles stimulate the macrophages to produce growth factors associated with systemic sclerosis, a hypothesis which could be tested.

The reports by Malo et al and Vandenplas et al describe new causes of occupational asthma. They overcome the major confounding factors that can lead to spurious results. Both involve exposure to substances which could be acting as direct irritants (sodium metabisulphite and welding fumes). It is much easier to show that an agent causes asthma than systemic sclerosis as challenge tests are available. Both authors used single exposures with measurements of lung function for several hours afterwards. False positive results can result from incremental doses given every few minutes until a reaction occurs. Both used control exposures degree of non-specific responsiveness. Only Vandenplas et al, however, measured exposure levels in the workplace and neither measured levels during the challenges. It is necessary to show that the challenge exposures are representative of the occupational exposures; reporting exposure levels also helps to extrapolate the results to other work situations.

The difference between asthma induced by allergic and presumed irritant mechanisms is becoming very blurred. It may be that irritants can also induce hypersensitivity, or that the resulting asthma induced by either mechanism is able to run the same course. Occupational asthma has been documented with a number of biocides which are likely to be denaturing proteins, perhaps forming neo-antigens. Examples include formaldehyde, ${ }^{45}$ glutaraldehyde, ${ }^{6}$ isothiozolinones, ${ }^{7}$ chlorhexidine ${ }^{8}$ chloramine $\mathrm{T},{ }^{9}$ and benzalkonium chloride. ${ }^{10}$ This type of reaction may allow an "irritant" to become an allergen. Chlorine itself may induce long lasting asthma after a single exposure. The pathology has shown basement membrane thickening which is greater than in occupational asthma ${ }^{11}$ without the eosinophil infiltration. Some regard irritant-induced asthma at work as a different (and by implication less worrying) disease than that mediated by specific IgE. There is accumulating evidence that this view warrants reappraisal.

1 Rodnan GP, Benedek TG, Medsger TA, Jr., Cammarata RJ. The association of progressive systemic sclerosis (scleroderma) with coal miners' pneumoconiosis and other forms of silicosis. Ann Intern Med 1967;66:323-34.

2 Ward AM, Udnoon S, Watkins J, Walker AE, Darke CS. Immunological mechanisms in the pathogenesis of vinyl chloride disease. $B M F$ 1976;1:936-8.

3 Harris DK, Adams WG. Acro-osteolysis occurring in men engaged in the polymerization of vinyl chloride. $B M F$ 1967;3:712-4

4 Hendrick DJ, Lane DJ. Formalin asthma in hospital staff. $B M \mathcal{F} 1975 ; 1: 607-8$

5 Burge PS, Harries MG, Lam WK, O'Brien IM, Patchett P. Occupational asthma due to formaldehyde. Thorax 1985; 40:255-60.

6 Gannon PFG, Bright P, Campbell M, O'Hickey SP, Burge PS. Occupational asthma due to glutaraldehyde and formaldehyde in endoscopy and $x$ ray departments. Thorax aldehyde in end

7 Nagorka R, Rosskamp E, Seidel K. Air conditioning assessment of humidification units. Off Gesundh-Wes 1990; 52:168-73.

8 Layton GT, Stanworth DR, Amos HE. The incidence of IgE and IgG antibodies to chlorhexidine. Clin Exp Allergy 1989;19:307-14.

9 Bourne MS, Flindt MLH, Walker JM. Asthma due to industrial use of chloramine. BMF 1979;2:10-12.

10 Burge PS, Richardson MN. Occupational asthma due to indirect exposure to lauryl dimethyl benzyl ammonium indirect exposure to lauryl dimethyl benzyl ammonium
chloride used in a floor cleaner. Thorax 1994:49:842-3.

11 Gautrin D, Boulet LP, Boutet M, Dugas M, Bhérer L, L'Archévêque $\mathrm{J}$, et al. Is reactive airways dysfunction syndrome a variant of occupational asthma? $\mathcal{F}$ Allergy Clin Immunol 1994;93:12-22. \footnotetext{
on separate days with similar measurements of lung function showing that the challenge result is specific. Both performed similar challenges on non-exposed subjects, controlling for the

Occupational Lung
Disease Unit,
Bordesley Green East, UK

P S Burge

S Burge
} 